\title{
Reconstruction assessment of historical land use: A case study in the Kamo River basin, Kyoto, Japan
}

\section{AUTHOR(S):}

Luo, Pingping; Takara, Kaoru; Apip; He, Bin; Nover, Daniel

\section{CITATION:}

Luo, Pingping ... [et al]. Reconstruction assessment of historical land use: A case study in the Kamo River basin, Kyoto, Japan. Computers \& Geosciences 2014, 63: 106-115

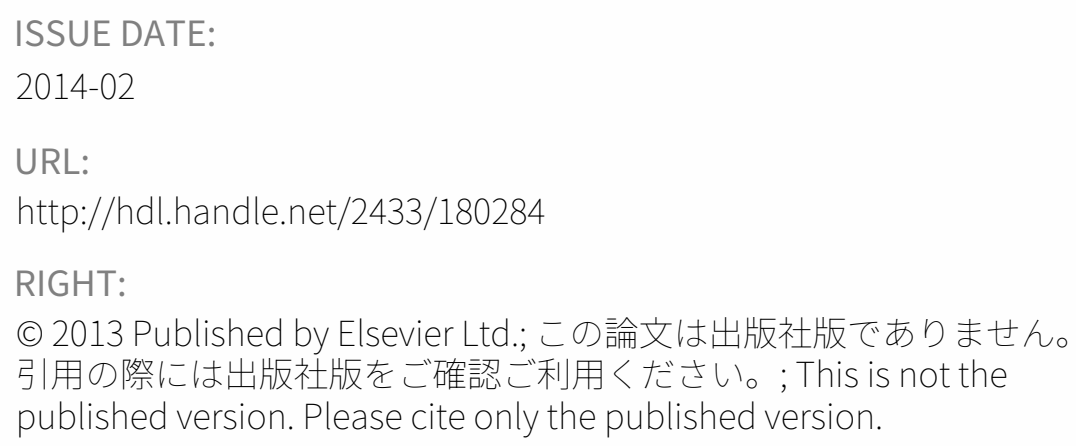




\title{
Reconstruction assessment of historical land use:
}

\section{a case study in the Kamo River basin, Kyoto, Japan}

\author{
Pingping Luo ${ }^{1)}$, Kaoru Takara ${ }^{2)}$, Apip $^{2), 3)}$, Bin $\mathrm{He}^{2), 4)}$ and Daniel Nover ${ }^{5)}$ \\ 1) JSPS Postdoctoral Fellowship, Disaster Prevention Research Institute (DPRI), Kyoto University, Gokasho, Uji City, Kyoto \\ 611-0011, Japan, Telephone: +81774384005 Fax: +81774384130, E-mail: robertluoping@ flood.dpri.kyoto-u.ac.jp \\ 2) Disaster Prevention Research Institute (DPRI), Kyoto University, Gokasho, Uji-shi, Kyoto 611-0011, Japan \\ 3) Research Center for Limnology, Indonesian Institute of Sciences (LIPI), Indonesia \\ 4) Center for Promotion of Interdisciplinary Education and Research, Educational Unit for Adaptation and Resilience for a \\ Sustainable Society, Kyoto University, Gokasho, Uji-shi, Kyoto 611-0011, Japan \\ 5) AAAS Science and Technology Policy Fellow, U.S. Environmental Protection Agency, Global Change Research Program, \\ Washington D.C., WA, USA
}

\begin{abstract}
Reconstruction assessment of historical land use can be useful for understanding historical conditions and the impact of long-term land-use change. This study establishes a new method to estimate historical land use based on a set of basic rules generated from the comparison of present land-use and historical documents. This method has been formalized in the paleo-land-use reconstruction (PLUR) program, allowing users to quickly reconstruct historical land use using historical information. The 1843, 1902 and 1927 historical land use conditions were generated using the PLUR model for the Kamo River basin (KRB). Our results show that between 1902 and 1976, three golf courses (Ohara Public course, Kamigamo course and Funayama course) replaced forest land in the KRB. As a result of agricultural development, the area occupied by paddy fields in 1843 was $2.48 \mathrm{~km}^{2}$ less than that in 1902 . Urban areas increased from 1843 to 1976, mainly reflecting declining coverage of paddy fields after 1902. The approach presented in this study can be used to support land-use change analyses and reconstruction of paleo-hydrology. This study also provides a discussion of the major drivers of land use change.
\end{abstract}

Keywords: historical land use, reconstruction, historical document, GIS, Kyoto

\section{If you would like to cite this paper please use this citation.}

Pingping LUO, Kaoru Takara, Apip, Bin He, Daniel Nover, Reconstruction assessment of historical land use: a case study at the Kamo River basin, Kyoto, Japan, Computers \& Geosciences 63, 106-115, DOI: 10.1016/j.cageo.2013.07.024, 2013. 


\section{Introduction}

Rapid urbanization has driven significant changes in environmental conditions and land-use between the late Modern era and the present. Land-use change and environmental degradation have affected flood frequency, water quality, as well as ecosystem health in general. Reconstruction of historical land use is an essential exercise for evaluating the effect of land-use change on hydrology, particularly for periods that predate modern hydrologic monitoring systems.

Recent studies have focused on the impact of land-use change on catchment hydrology (Siriwardena et al., 2006; Mao et al., 2009) and the quantification of the influence of land-use and water management on streamflow (Romanowicz et al., 2011). An assessment of the long-term effect of land-use change on hydrology and solute budgets was conducted on small catchments in Amazonia (Germer et al., 2009). A series of four studies focused on assessing the impact of land-use change on hydrology by ensemble modeling (LUCHEM). The first is a model intercomparison using current land-use (Breuer et al., 2009). The second presents ensemble combinations by simple averaging and a comparison of predictions using single-models (involves the use of a number of realizations of a single deterministic model) and multi-model ensembles (involves several different deterministic models) (Viney et al., 2009). The third and fourth present land-use change scenario analysis (Huisman et al., 2009) and the effect of spatial resolution and distribution of model input data on the results of regional-scale land-use scenarios (Bormann et al., 2009). Wijesekara et al. (2011) developed a method for extending assessments of land-use change impacts on hydrologic processes into past and future periods. However, most assessments of land-use change impacts consider only the past several decades. A land-use change impact assessment on hydrology and sediment (Ward et al. 2008) included a simple introduction to the reconstruction of historical land use, underscoring the importance of historical land use reconstruction for land-use change impact 
assessments and simulations of paleo-hydrology.

The reconstruction of historical land use and environmental conditions includes the reconstruction of paleo-channels, paleo-land-use/landscape and the paleo-environment. Schumm (1968) investigated paleo-channels of riverine plains of the Murrumbidgee River, Australia and reconstructed the shape of the cross-section and the slope of the paleochannel using alluvial sediment cores in the river valley. A newly-discovered spatial correlation between paleo-channels and nearshore morphology provided graphical correlation and statistical cross-correlation analyses for the reconstruction of paleo-channels (Browder and McNinch, 2006). Ward et al. (2008) described a way to generate paleo-land-use based on CORINE data (Land Cover 2000 (CLC2000) EEA, Copenhagen, 2001), census data, historical records, and pollen analyses. Several studies focus on the use of historical census information in Belgium (WL, 1994a), the Netherlands (Knol et al., 2004) and France (Dutoo, 1994). Pollen analysis was mainly used for simulating the period from 4000 to $3000 \mathrm{BP}$ (Bunnik, 1995; Gotje et al., 1990; Henrard, 2003). Kuzyakov et al. (2006) investigated paleo-environmental reconstructions using isotopic exchange of carbonate re-crystallization in soil. Field observation approaches can be used as a foundation for paleo-environmental reconstruction (Saengscrichan et al., 2011). Multiple techniques including sediment size distribution, stable carbon isotopes, pollen, and phytolith analyses can also be used for paleo-environmental reconstruction (Bement et al., 2007). However, the above methods are expensive, time consuming, and difficult. At present, there is no simple, detailed method for reconstructing historical land use based on historical information and paper maps.

The Kamo River Basin (KRB) is located in Kyoto, the former capital of Japan (794AD to 1868AD). Due to Kyoto's long history, there are many historical documents related to the Kyoto landscape. In recent years, the Virtual Kyoto project, part of a 21st Century Center of Excellence (COE) project called "Kyoto Art Entertainment Innovation Research" in 
Ritsumeikan University was funded by the Ministry of Education, Culture, Sports, Science and Technology (MEXT) (Nakaya et al., 2010). The "Virtual Kyoto" research integrates Geographical Information System (GIS) and virtual reality (VR) technologies to develop a 4 Dimension (4D)-Geographic Information System (GIS) model of Kyoto in order to view the city's modern landscape (17th to 20th centuries) and hindcast the landscape to the Heian period (8th to 12th centuries) (Yano et al., 2008). Isoda et al. (2009) used historical documents from Edo era Kyoto to create large-scale urban 3D models in which the landscape of the entire Edo era city is reconstructed. This study describes the urbanization driven changes in socio-economic factors and urban structures observed in the Meiji, Taisho and Showa periods in Kyoto. Previous reconstructions of the Kyoto historical environment focused on urban areas. Reconstruction of historical land use at the river basin scale on the basis of historical documents has not yet been done. Compared with previous methods employed in the KRB, our approach is simple and integrates methods for addressing historical information including socio-economic indicators, paper maps and present land use.

The main objective of this study is to develop a method for reconstruction of historical land use. Using historical information (historical social structure, historical environment, old books, drawings and historical documents) and present digital land-use data, we have developed basic rules that together are incorporated in the paleo-land-use reconstruction (PLUR) program. We present the results of an application of PLUR for reconstructions at the KRB for the years 1843,1902 and 1927. The methods and results of this study may be useful for reconstruction of paleo-hydrology and land-use change impact assessments. The primary drivers of land-use change are also discussed.

\section{Study Site}

The KRB is used as a case study site for the reconstruction of historical land use. The KRB is 
a sub-basin of the Katsu River basin (Fig. 1). The Kamo River passes through Kyoto, the capital of Japan from 794 AD to 1868 AD (Ibbitt et al., 2002). There are many historical documents describing various aspects of this area and Kyoto, including land use, geography, weather, disasters, etc. that can be used for historical land use reconstruction. The riverbank of the Kamo is popular with tourists and residents for many activities such as sightseeing during Sakura (cherry blossoms) blooms, fishing and walking. There are some public walkways around this riverbank which are opened for public access and cherry blossom festival during the dry season. During heavy rainfall, the pathways become flooded and access is restricted. Located near the upper stream of the KRB, the Sajikigatake mountain area forms the boundary of Kumogahata village and Keihoku village in the northern ward of Kyoto. The length of the Kamo River is $\sim 31 \mathrm{~km}$. The area and highest elevation of the KRB is $\sim 210 \mathrm{~km}^{2}$ and $896 \mathrm{~m}$ respectively.

\section{Present and historical land-use data}

We collected 1976 land-use data for the KRB from the Japan Ministry of Land, Infrastructure, Transport and Tourism (MLIT) to represent present land-use (Fig. 2). Table 1 shows the classifications and the area of each land-use type in 1976. Forests occupy 74\%, building sites A and B occupy $14 \%$, and paddy fields occupy $3.8 \%$ of total land area. Building type A is high density residential, including residential streets, free-standing buildings and housing area with side lengths of more than $50 \mathrm{~m}$, as well as other tall and large buildings. Building type B is medium or low density residential, including free-standing buildings and housing with side lengths less than $50 \mathrm{~m}$.

In this study, we use 1902 as the target for land-use reconstruction. Historical geographic information was collected from the Japan map center (Fig. 3) in order to reconstruct 1902 land-use. Although this document included names of numerous locations, the northern part of 
the map had low resolution, and place-names could not be clearly identified. Major places are identified in Fig. 3 to ensure the accuracy of the reconstruction. Six major locations were identified to reference the 1902 paper map to the 1976 land-use map: the Kyoto Imperial Palace (NO.1), the Shokoku Temple and Doshisha (NO.2), Kyoto Textile Company (NO.3), Changed area (eastern bank) (NO.4), Changed area (north-east bank) (NO.5), Sanjo-dori (NO.6), and Shijo-dori (NO.7). Historical paper maps of Kyoto were used because the city is the part of the KRB that has changed most dramatically.

In order to understand the historical condition of the KRB, we give a brief introduction of Kyoto's history for the period 1881AD-1914AD and around 1980 as below:

a). The Japanese economy was disturbed by political troubles in the 1870 's. In response, the minister of finance introduced central banking reforms based on the European model to restore order to the financial system, balance the budget, and restore parity between banknotes and the silver backing. In addition to the financial system, reforms changed policies related to taxation of alcohol, tobacco and land. These changes were so broad and dramatic that they affected nearly every branch of agricultural, industrial and commercial life (Allen 2003). Tension between urban and agricultural land-uses began amidst rapid urbanization beginning in the 1960s. The population of Kyoto was 640,000 in 1918, 1 million in 1932 and 1.42 million in 1969 (KyotoMarumie, 2012). Agricultural fields were rapidly converted to urban land-uses as a result of increasing populations.

b). Kyoto has a long history of cartographic representation. The mapping of Kyoto ranges from hand drawn pictures to surveyed maps. The most famous picture map, drawn by KANO, Eitoku in 1574, is called 'Rakuchu-Rakugai $\mathrm{Zu}$ ' and is $1.6 \mathrm{~m}$ high by $3.6 \mathrm{~m}$ wide (Hasegawa, 2005). The main part of this picture is shown during the New Year's celebration at the Imperial Palace. The earliest printed maps of Kyoto were published in the mid 1620s in a collection of 491 sheets. The oldest printed urban map in Japan is called 'The description of 
Kyoto' published by woodcut in 1624-26. The first detailed manuscript maps of Kyoto with a 1:1500 scale were drawn in 1637 and 1643 by the Master of Architecture, the House of Nakai (Hasegawa, 2005). Another type of pictorial surveyed map had hand color and included the city suburbs. Kichiei HAYASHI was the major map publisher during the latter half of the 17th century. The first edition of Kichiei, printed in 1686, shows the blocks inside of Kyoto as blank, while the shrines and temples, mountains and rivers were printed in vivid color. The first mapping of early modern Kyoto was published with multi-color prints in 1812 by TAKEHARA, Kobei. Published toward the end of the Meiji period, the 1902 pictorial surveyed map included a detailed description of Kyoto and the suburbs with detailed land uses differentiated using different marks and multi-color prints.

\section{Proposed Methodology for Reconstruction of Historical land use}

The approaches used for building Virtual Kyoto as a part of the 21 st Century Center of Excellence (COE) project "Kyoto Art Entertainment Innovation Research" in Ritsumeikan University (Nakaya et al., 2010) are presented briefly below:

(1) Digitizing Archives. Based on Kyoto area studies, history of classical entertainment, traditional crafts, digital library and history of religion and thought.

(2) Building Geographic Information Systems (GIS) database.

(3) Building Virtual Kyoto in spatial and temporal scales.

(4) Developing software infrastructure for virtual reality and interface database network.

Virtual Kyoto was designed for high resolution 3D view, and cannot be applied to larger scale hydrologic studies. We present a new method using a simple paleo-land-use reconstruction (PLUR) program with high speed computation to reconstruct historical land use at the river basin scale based on historical information (historical social structure, 
historical environment, old books, drawings and historical documents) and present land-use.

There are six steps necessary for historical land use reconstruction in the KRB (Fig. 4). The following describes the six steps in detail:

(1) We collected historical information, previous land-use data and paleo-society information. Historical information included geographic paper maps, books and historical documents. Land use data from 1976 was stored in digitized format. Historical information related to urban planning, population and socio-economic conditions of Kyoto were archived and used to represent paleo-society. The 1976 land use is the oldest digitized data available and is used as the input to generate a basal map for the geometric correction.

(2) Based on information from step 1, areas where land-use has changed were delineated and built into the vector data (feature and polygon). The process of vector data delineation is broken into three steps:

a) Significant places are used to match 1976 land-use to 1902 historical documents, including: the Kyoto Imperial Palace (NO.1), the Shokoku Temple and Doshisha (NO.2), Kyoto Textile Company (NO.3), Changed area (eastern bank) (NO.4), Changed area (north-east bank) (NO.5), Sanjo-dori (NO.6), Shijo-dori (NO.7) (Fig. 3).

b) According to comparisons of past and current maps, we find that NO.4 and NO.5 were mostly paddy fields in the 1902 paper map but were mainly residential according to the 1976 land-use map.

c) We drew the changed features and polygons based on changes observed during the analysis of the information in step 1.

(3) Geometric correction is necessary to modify the shape of the vector data using several basic rules described below and comparison to 1976 land-use. In this step, 
we consider the history of urban construction from 1902 to 1976 . The new vector data is created after the geometric correction. optimized here for the KRB, these rules can be used to conduct similar studies in other sites. Detailed explanation of the rule-making process is as follows:

a) Historical books, paper maps and present digital land-use data are collected.

b) Using the results of step a), we analyze digital land-use data and historical paper maps, and check historical books to identify detailed historical information such as temples, railways, golf courses, etc.

c) Unchanged areas are used to synchronize historical and contemporary land-use information.

d) Basic rules emerge through a systematic analysis of the results of step c). based on collected historical documents.

The basic rules are as follows:

a) The 1976 land-use is used as a base map.

b) Temples have not moved.

c) The area of forest cover is larger in the paleo-period than that in the present period. 
input files containing 1976 land-use and the new vector data are given to the PLUR program which contains an algorithm for jointing two raster files. This program also considers the historical condition of the paleo-period based on basic rules and historical information.

(5) After step 4, the reconstructed historical land use is output from the PLUR program. The detailed information of each classification for the reconstructed historical land use is also given.

(6) Finally, the 1976 land-use and the newly created 1902 historical land use are used for the land-use change analysis. The area and the changed area of the various land uses from the two periods are calculated in this step.

The historical land use of 1843 and 1927 are generated according to the same procedure as that used for reconstruction of 1902 land-use.

\section{Application of the PLUR Program and Discussion}

Reconstruction of the 1843, 1902 and 1927 land-use data in the KRB was conducted as an application of the PLUR program and compared with 1976 land-use. The following discussion focuses on several of the factors that drive land use change between the historical and contemporary conditions.

\subsection{Forest}

Table 2 shows that forest area decreased from 1843 to 1976, and the area of forest in 1843 was $3.78 \mathrm{~km}^{2}$ larger than in 1902. After the government assumed ownership of forests beginning in the Meiji Era (1869-1912), villagers lost interest in forest stewardship and deforestation ensued (Zorn, T., 1999). In 1897, the federal government established the Forest Law which included the creation of protected forest areas and partially controlled deforestation. Table 2 shows that rapid deforestation from 1843 to 1902 may have been caused by forest owners and farmers in the Meiji Era. 
Table 1 shows that $4.08 \%\left(5.71 \mathrm{~km}^{2}\right)$ of forest area was lost from 1902 to 1976 (Table 1) . This decrease in forest area resulted from conversion of forest area to three golf courses and a housing development in the north-east mountain area. The construction of golf courses in Kyoto began in 1946 (Takeda, 2006). The area of the golf course was increased by cutting forest area. The speed of deforestation from 1902 to 1927 decreased, possibly due to protective action after the Forest law was instituted in 1897.

\subsection{Rice Field}

Rice field area in 1976 decreased by $12.49 \mathrm{~km}^{2}$ from $19.33 \mathrm{~km}^{2}$ to $6.84 \mathrm{~km}^{2}$ since 1902 . Table 1 show that the percent coverage of rice fields in 1976 decreased from $10.72 \%$ to $3.79 \%$. In 1902, during the Meiji period, agriculture (especially paddy fields) occupied a higher percentage of the total land area (Akai, 1974). Based on the 1902 historical document, there are three main areas of forest that changed into paddy fields when compared with the 1976 land-use map.

The first area, located east of the Kamo River, starting from south of location NO.3 going to the north (Fig. 3) and starting from the Kamo River east bank to Higashiyama (shown at NO.4 and NO.5 in Fig. 3), was covered by paddy fields in 1902. The temples and shrines (Yoshida shrine, Kumono Shrine, Haruhi shrine and so on), Kyoto university campus and the Kyoto Textile Company also existed at NO.4 and NO.5 in 1902.

The second area is located at the west bank of the Kamo River, starting from the north boundary of NO.2 area shown in Fig. 3 to the north, starting from the west of the NO.5 area to the west. The area of the second part is mostly covered by paddy fields except some temples, shrines and other sites, including the Shokamo shrine, Imamiya shrine, Iketsuya Lake, and etc.

The third area is located at the north-east of the Kamo River, starting from the north of the 
first changed area to the north of the KRB. In this area, two golf courses were constructed between 1902 and 1976 and some paddy field area was urbanized over the same time period. The land-uses 'waste land', 'other field' and 'lake area' did not change categories between 1902 and 1976.

Table 2 and Fig. 6 show that rice field area in 1843 is $2.48 \mathrm{~km}^{2}$ less than that in 1902 due to agricultural development. There is a decreasing trend in paddy field area coverage between 1902 and 1976. The area of paddy fields in 1902 is $6.5 \mathrm{~km}^{2}$ and $12.49 \mathrm{~km}^{2}$ greater than that in 1927 and 1976 which may be due to the urbanization of Kyoto.

\subsection{Urban Area}

The urban area designated building site A increased by half from $8.89 \mathrm{~km}^{2}$ in 1902 to 16.76 $\mathrm{km}^{2}$ in 1976 , and the urban area designated building site B in 1976 increased by $7.56 \mathrm{~km}^{2}$ (Table 1) compared with that in 1902. In Table 1, the percentage of building site A and B increased from $4.93 \%$ to $9.29 \%$ and from $0.84 \%$ to $5.03 \%$ respectively.

Looking at urban areas of Kyoto, some changes have taken place in the north part from the Shokoku temple and the NO.4 and NO.5 areas. There are some large uniform roads such as Sanjo-dori, Shijo-dori and Gojo-dori which run directly across the city from west to east and also over the Kamo River extending to the east bank. The Nijo-dori starts from the front of Nijo castle to the east bank of the Kamo River.

Urban areas increased slightly by $0.64 \mathrm{~km}^{2}$ and $0.56 \mathrm{~km}^{2}$ for the building sites A and B from 1843 to 1902 . Increases in the area of building sites A and B may come from the deforested area. The area of building sites A and B in 1927 is 4.88 and $1.94 \mathrm{~km}^{2}$ greater than that area in 1902, and the area of building sites A and B in 1976 is 2.99 and $5.62 \mathrm{~km}^{2}$ greater than that area in 1927. After 1902, the urbanized area comes from the decreased area of paddy fields. The change in area of building site $\mathrm{A}$ is much more than the change in area of building 
site $\mathrm{B}$ in 1927, and the change in area of building site B is much more than the change in area of building site A in 1976. These observations likely stem from urbanization in Kyoto driven by rapid population growth from 1927 until after the second Would War (Fig. 7), and the construction of high-density residential housing after 1945. The urban area of Kyoto city has extended somewhat from the west bank of the KRB to Higashiyama located at the east bank of the KRB (the right side close to NO.6 and NO.7 in Fig. 3).

\subsection{Traffic Area}

Traffic area in 1976 increased $0.82 \mathrm{~km}^{2}$ compared with 1902 land-use. The percentage of traffic area in 1976 increased from $0.80 \%$ in 1902 to $1.25 \%$. The increase in traffic area in 1976 is mainly due to decreases in two parts in the north of Kyoto. The first is related to the Eizan Main Line of the Eizan Electric Railway located in northeast Kyoto. Due to this railway line, which began running in 1925 (Tanaka et al., 2004), the traffic area around this route was absent in 1902. The second part is located in the north-west of Kyoto. Comparisons between Fig. 2 and Fig. 3 reveal that some of the big roads north of Shokoku temple (NO.2) did not exist in the reduced urban area of 1902.

Fig. 5 shows that there is much more traffic area 1927 than in 1902. Some part of the Eizan Main Line of the Eizan Electric Railway is shown in the 1927 land use map. The traffic area of 1843 is $0.08 \mathrm{~km}^{2}$ less than that in 1902 .

\subsection{Other Sites}

In Table 1, the area of other sites in 1902 was reduced $0.45 \mathrm{~km}^{2}$. In Table 1 and Fig. 5, the percentage of other sites in 1902 changed to 4.15\%. In the 1976 land-use map, MLIT defines golf courses as land-use type "other sites."The "other sites" increased by $1.04 \mathrm{~km}^{2}$ from 1927 to 1976 because of the construction of the golf course after 1946 (the Ohara Public course, 
Kamigamo course and Funayama course). The area of "other sites" in 1843 is the same as in 1902. The area of other sites in 1927 is $0.26 \mathrm{~km}^{2}$ greater than that in 1902 which may be the result of deforestation.

\subsection{History and Change of the Kyoto Urban Planning}

The history of building height policy in Kyoto city contributed to changing densities of urban land use. Zoning limits and land use types in Kyoto were divided into residential, commercial, quasi-industrial and industrial in 1924. Due to changes in urban planning, the urban area of 1902 land use is quite different from that of 1976. We found that the population increased dramatically from 1899 to 1970 (Fig. 7). The population density in 1902 was much lower than that in 1976. Tall buildings in Kyoto city also increased from 1902 to 1976 . The building density of the city also increased due to increasing population from 1902 to 1976 . Height rules had a great impact on construction around historic streets and tourist spots. Urban areas also increased significantly from 1902 to 1976 with increasing population.

\subsection{Discussion}

Three land use types (river area, lake and marsh, and other fields) maintained the same coverage from 1843 to 1976 . The land use types of waste land and other sites did not change significantly from 1843 to 1976 . Fig. 6 shows four land use types with significant changes, including building types $\mathrm{A}$ and $\mathrm{B}$, arterial traffic sites and rice fields. For building site $\mathrm{A}$, the area did not change much from 1843 to 1902, but increased significantly between 1927 and 1976. The area of building site B was very low in 1843 and 1902 and increased more than one time in 1927 and four times in 1976. The area of arterial traffic sites increased slightly from 1843 to 1976 due to the urbanization of Kyoto. Rice field area was $16.85 \mathrm{~km}^{2}$ in 1843 , increased $2.48 \mathrm{~km}^{2}$ in 1902 because of the development of agriculture, and decreased from 
1927 to 1976 due to urbanization and population growth (Fig. 7).

Based on data shown in Fig. 7, we found that the population in Kyoto increased significantly from 1899 to 1976 , and the population of 1976 increased by more than a million people from 1899. Population growth was likely the main factor leading to changes in the social structure and environmental conditions in urban areas. The results of historical land use reconstruction show that agricultural area, which played an essential role in the socio-economics of Kyoto, occupied approximately $10 \%$ of the total KRB in 1902.

The PLUR program is effective in a river basin with urban areas including a long history and a lot of historical information. Reconstruction of historical land use for river basins that lack historical information require alternative analyses in combination with the PLUR program to more accurately reflect historical conditions. Basic rules can be developed according to the method described above and used as the input for the PLUR program in other study sites. PLUR can be applied at any study site based on the development of basic rules and the framework of the historical land use reconstruction process (Fig. 5).

\section{Conclusions}

Historical land use reconstruction studies are useful for estimating land-use in past periods, historical environmental conditions, and the relationship between historical land use and paleo-social structure. In this study, we provide a simple program which can use historical information (historical social structure, historical environment, old books, drawings and historical documents) and paper geographic maps to reconstruct historical land use. This program can be applied at the river basin scale where ample historical documents exist. We present an application of the PLUR program for 1843, 1902 and 1927 historical land use reconstruction. The results of this application show that forest and paddy field were greater, and urban areas, traffic areas and other sites in 1843, 1902 and 1927 were less than that in 1976 land-use. The most significantly decreased land-use type is paddy fields. The most 
affected areas included forest which was developed into the three golf courses and the Eizan Main Line railway. Urbanization and population growth from 1927 to World War II and construction of high-density residential housing after 1945 combined with changes to civil society, laws, and policies were the main drivers of land-use change in Kyoto. This analysis is adaptable to other study sites and PLUR can easily be adjusted to assess the impact of land-use change in the past period and to reconstruct paleo-hydrology in other sites with long historical records.

\section{Acknowledgement}

This study was supported by the Postdoctoral fellowship of the Japan Society for the Promotion of Science (P12055), JSPS KAKENHI Grant Number 24·02055, Designing Local Frameworks for Integrated Water Resources Management at the Research Institute for Humanity and Nature (RIHN), JSPS Grant-in-Aid for Scientific Research(A) Grant Number 24248041, the Kyoto University Global COE program on "Sustainability/Survivability Science for a Resilient Society Adaptable to Extreme Weather Conditions", and Inter-Graduate School Program for Sustainable Development and Survivable Societies (GSS), MEXT Program for Leading Graduate Schools 2011-2018. The authors are grateful for their support. We also thank Mr. Pedro Luiz Borges Chaffe and Mr. Netrananda Sahu for providing comments on this paper.

\section{References}

Allen, G.C., 2003. A short economic history of modern Japan 1867-1937. Routledge, 11New Fetter Lane, London EC4P 4EE. 
408 Bement, L.C., Carter, B. J., Varney, R.A., Cummings, L. S., Sudbury, J. B., 2007. 409 Paleo-environmental reconstruction and bio-stratigraphy, Oklahoma Panhandle, USA. 410 Quaternary International 169-170, 39-50.

411 Bormann, H., Breuer, L., Gra“ff, T., Huisman, J.A., Croke, B., 2009. Assessing the impact of 412 land-use change on hydrology by ensemble modelling (LUCHEM) IV: Model sensitivity to 413 data aggregation and spatial (re-)distribution. Advances in Water Resources 32, 171-192.

414 Breuer, L., Huisman, J.A., Willems, P., Bormann, H., Bronstert, A., Croke, B.F.W., Frede, 415 H.-G., Graff, T., Hubrechts, L., Jakeman, A.J., Kite, G., Lanini, J., Leavesley, G., Lettenmaier, 416 D.P., Lindstrom, G., Seibert, J., Sivapalan, M., Viney, N.R., 2009. Assessing the impact of 417 land-use change on hydrology by ensemble modeling (LUCHEM). I: Model intercomparison 418 with current land-use. Advances in Water Resources 32, 129-146.

419 Browder, A. G., McNinch, J. E., 2006. Linking framework geology and nearshore 420 morphology: Correlation of paleo-channels with shore-oblique sandbars and gravel outcrops. Marine Geology 231, 141-162.

422 Bunnik, F. P. M., 1995. Pollenanalytische Ergebnisse zur Vegetationsund Land-wirtschaftsgeschichte der J"ulicher L"oßb"orde von der Bronzezeit bis in die fr"uhe Neuzeit, Bonner Jahrb“ucher, 195, 313-349.

Dutoo, D., 1994. Onderzoeksproject Watersnood Maas. Het areaal onder bos in het Franse maasbekken van 1908 tot 1988, Universiteit Gent, Gent, Belgium.

EEA, 2001, Sustainable water use in Europe. Part 3: Extreme hydrological events: floods and droughts, Environmental issue report No. 21, EEA, Copenhagen, Denmark, http://reports.eea.europa.eu/Environmental Issues No 21/en.

430 Germer, S., Neill, C., Vetter, T., Chaves, J., Krusche, A. V., Elsenbeer, H., 2009. Implications Amazonia. Journal of Hydrology 364, 349-363. 
Gotj'e, W., Van Wayjen, M. C. A., and Van Geel, B., 1990. A palynological study of a Holocene deposit from Grand-Bongard (Hautes- Fagnes, Belgium), Geologie en Mijnbouw, $69,227-241$.

Henrard, D., 2003. The Mesolithic of the Ourthe Basin: Landscape settlement and Neolithisation, L'anthropologie, 107, 615-644.

Huisman, J.A., Breuer, L., Bormann, H., Bronstert, A., Croke, B.F.W., Frede, H.-G., Graff, T., Hubrechts, L., Jakeman, A.J., Kite, G., Lanini, J., Leavesley, G., Lettenmaier, D.P., Lindstrom, G., Seibert, J., Sivapalan, M., Viney, N.R., Willems, P., 2009. Assessing the impact of land-use change on hydrology by ensemble modeling (LUCHEM) III: Scenario analysis. Advances in Water Resources 32, 159-170.

Ibbitt R., Takara K., Desa M.N.B.M. \& Pawitan H. (eds.) Catalogue of Rivers for Southeast Asia and the Pacific, IV, The UNESCO-IHP Regional Steering Committee for Southeast Asia and the Pacific, March 2002, 110-124, 2002.

Isoda, Y., Tsukamoto, A., Kosaka, Y., Okumura, T., Sawai, M., Yano, K., Nakata, S., and Tanaka, S., 2009. Reconstruction of Kyoto of the Edo era based on arts and historical Documents: 3D urban model based on historical GIS data. International Journal of Humanities and Arts Computing 3 (1-2), 21-38.

Knol, W. C., Kramer, H., and Gijsbertse, H., 2004. Historisch grondgebruik Nederland: een landelijke reconstructie van het grondgebruik rond 1900, Alterra report 573, Alterra, Wageningen, The Netherlands, http://library.wur.nl/wasp/bestanden/ LUWPUBRD 00328279 A502 001.pdf.

Kuzyakov, Y., Shevtzova, E., Pustovoytov, K., 2006. Carbonate re-crystallization in soil revealed by ${ }^{14} \mathrm{C}$ labeling: Experiment, model and significance for paleo-environmental reconstructions. Geoderma 131, 45-58.

Kyoto Marumie, accessed on July 06, 2013. http://www.k-marumie.com/kyoto/population/. 
Mao, D., Cherkauer, K. A., 2009. Impacts of land-use change on hydrologic responses in the Great Lakes region. Journal of Hydrology 374, 71-82.

Nakaya, T., Yano, K., Isoda, Y., Kawasumi, T., Takase, Y., Kirimura, T., Tsukamoto, A., Matsumoto, A., Seto, T., and Iizuka, T., 2010. Virtual Kyoto Project: Digital Diorama of the Past, Present, and Future of the Historical City of Kyoto. Lecture Notes in Computer Science, Vol. 6259, 173-187.

Romanowicz, R. J., Osuch, M., 2011. Assessment of land-use and water management induced changes in flow regime of the Upper Narew. Physics and Chemistry of the Earth, doi:10.1016/j.pce.2011.04.012.

Saengsrichan, W., Charoentitirat, T., Meesook, A., Hisada, K., Charusiri, P., 2011. Paleo-environments and tectonic setting of the Mesozoic Thung Yai Group in Peninsular Thailand, with a new record of Parvamussium donaiense Mansuy, 1914. Gondwana Research $19, \quad 47-60$.

Schumm, S.A., 1968. River adjustment to altered hydrologic regimen-- Murrumbidgee River and palaeo-channels, Australia. US Geological Survey Professional Paper 598, Washington.

Siriwardena, L., Finlayson, B.L., McMahon, T.A., 2006. The impact of land-use change on catchment hydrology in large catchments: The Comet River, Central Queensland, Australia. Journal of Hydrology 326, 199-214.

Takeda, K., 2006. Kyoto Golf Club (Part1). Nikkei Business Publications http://www.nikkeibp.co.jp/style/golfers/special/kyoto/060726.html

Tanaka, N., Kawasaki, M. and Kameyama Y., 2004. Process of Urban Development based on the Railway Systems under the Modernization in Kyoto. Research Proceedings of Infrastructure Planning, JSCE, Vol. 21(2), 385-391. Available at http://library.jsce.or.jp/jsce/open/00041/2004/21-0385.pdf.

Viney, N. R., Bormann, H., Breuer, L., Bronstert, A., Croke, B.F.W., Frede, H., Graff, T., 
Hubrechts, L., Huisman, J.A., Jakeman, A.J., Kite, G.W., Lanini, J., Leavesley, G., Lettenmaier, D.P., Lindstrom, G., Seibert, J., Sivapalan, M., Willems, P., 2009. Assessing the impact of land-use change on hydrology by ensemble modelling (LUCHEM) II: Ensemble combinations and predictions. Advances in Water Resources 32 , 147-158.

WL, 1994. Onderzoek Watersnood Maas. Achtergrondrapport 1. Hydrolgie, Deel A + B.

Onderzoeksproject Watersnood Maas, Het Belgische stroombekken.Waterloopkundig Laboratorium, Delft, The Netherlands.

Ward, P.J., Renssen, H., Aerts, J.C.J.H., Van Balen, R.T., Vandenberghe, J., (2008) Strong increases in flood frequency and discharge of the River Meuse over the late Holocene: impacts of long-term anthropogenic land use change and climate variability. Hydrol Earth Syst Sci 12:159-175. www.hydrol-earth-syst-sci.net/112/159/2008.

Wijesekara, G.N., Gupta, A., Valeo, C., Hasbani, J.-G., Qiao, Y., Delaney, P., Marceau, D.J., 2011. Assessing the impact of future land-use changes on hydrological processes in the Elbow River watershed in southern Alberta, Canada. Journal of Hydrology, doi:10.1016/j.jhydrol.2011.04.018.

Yano, K., Nakaya, T., Isoda, Y., Takase, Y., Kawasumi, T., Matsuoka, K., Seto, T., Kawahara, D., Tsukamoto, A., Inoue, M., and Kirimura, T., 2008. Virtual Kyoto-4DGIS Comprising Spatial and Temporal Dimensions. Journal of Geography, Vol. 117 ( 2), 464-478.

Zorn, T., 1999. A forest political study on protection forests of Germany, Austria and Japan, Journal of the Faculty of Agriculture, Hokkaido University 69(2): 47-128 http://hdl.handle.net/2115/1315 


\section{List of Tables and Figures}

Table 1 Area of each land use (LU) in 1902 and 1976, and LU change between 1976 and 1902.

Table 2 Classification and the area for each land use type for 1976, 1927, 1902 and 1843.

Fig.1 Location and Digital Elevation Map (DEM) (original source from MLIT) of the KRB.

Fig.2 1976 Land-use (original source from MLIT) of the KRB (Building type A is high density residential, including residential streets, free-standing buildings and housing area with side lengths of more than $50 \mathrm{~m}$, as well as other tall and large buildings. Building type B is medium or low density residential, including free-standing buildings and housing with side lengths less than $50 \mathrm{~m}$.).

Fig.3 Example of Kyoto city land use in 1902 (original source from MLIT).

Fig.4 Framework of the historical land use reconstruction process (the detail description of the process on reconstructing the historical land use by using PLUR program).

Fig. 5 Land use map of 1976, 1927, 1902 and 1843 (land use map of 1843,1902, 1927 is reconstructed by using PLUR program, land use map of 1976 is obtained from MLIT).

Fig. 6 Land use change among 1843, 1902, 1927 and 1976 (including Building sites A and B, Traffic site and Rice field, Building type A is high density residential, including residential streets, free-standing buildings and housing area with side lengths of more than $50 \mathrm{~m}$, as well as other tall and large buildings. Building type B is medium or low density residential, including free-standing buildings and housing with side lengths less than $50 \mathrm{~m}$.).

Fig.7 Population of Kyoto city from 1899 to 1976 (Kyoto Marumie, 2013). 
533 Table 1 Area of each land use (LU) in 1902 and 1976, and LU change between 1976 and 1902.

535

\begin{tabular}{cccccc}
\hline LU code & LU name & 1902LU $(\mathbf{k m 2}) \mathbf{1 9 7 6} \mathbf{U} \mathbf{( \mathbf { k m 2 } )}$ & Changes of LU $(\mathbf{k m 2})$ & Percentage of change $(\%)$ \\
\hline 1 & Forest & 139.81 & 134.1 & -5.71 & -4.08 \\
2 & Building site A & 8.89 & 16.76 & 7.87 & 88.53 \\
3 & Building site B & 1.51 & 9.07 & 7.56 & 500.66 \\
4 & Arterial traffic sites & 1.44 & 2.26 & 0.82 & 56.94 \\
5 & River area & 1.53 & 1.53 & 0 & 0 \\
6 & Other sites & 6.64 & 7.94 & 1.3 & 19.58 \\
7 & Lake and marsh & 0.14 & 0.14 & 0 & 0 \\
8 & Waste land & 0.73 & 1.38 & 0.65 & 89.04 \\
9 & Rice field & 19.33 & 6.84 & -12.49 & -64.61 \\
10 & Other farm fields & 0.34 & 0.34 & 0 & 0 \\
\hline
\end{tabular}

536 Building type $\mathrm{A}$ is high density residential, including residential streets, free-standing

537 buildings and housing area with side lengths of more than $50 \mathrm{~m}$, as well as other tall and large

538 buildings. Building type $\mathrm{B}$ is medium or low density residential, including free-standing

539 buildings and housing with side lengths less than $50 \mathrm{~m}$. 
Table 2 Classification and the area for each land use type for 1976, 1927, 1902 and 1843.

566

\begin{tabular}{cccccc}
\hline \multirow{2}{*}{ ID } & Name & \multicolumn{4}{c}{ Land use area $\left(\mathbf{k m}^{\mathbf{2}}\right)$} \\
\cline { 3 - 6 } & & $\mathbf{1 8 4 3}$ & $\mathbf{1 9 0 2}$ & $\mathbf{1 9 2 7}$ & $\mathbf{1 9 7 6}$ \\
\hline 1 & Forest & 143.59 & 139.81 & 138.21 & 134.1 \\
2 & Building type A & 8.25 & 8.89 & 13.77 & 16.76 \\
3 & Building type B & 0.95 & 1.51 & 3.45 & 9.07 \\
4 & Arterial traffic area & 1.36 & 1.44 & 2.08 & 2.26 \\
5 & River area & 1.53 & 1.53 & 1.53 & 1.53 \\
6 & Other sites & 6.64 & 6.64 & 6.9 & 7.94 \\
7 & Lake and marsh & 0.14 & 0.14 & 0.14 & 0.14 \\
8 & Waste Land & 0.71 & 0.73 & 1.12 & 1.38 \\
9 & Rice field & 16.85 & 19.33 & 12.83 & 6.84 \\
10 & Other Fields* & 0.34 & 0.34 & 0.34 & 0.34 \\
\hline
\end{tabular}

* The area of other fields is supposed to be not changed. 


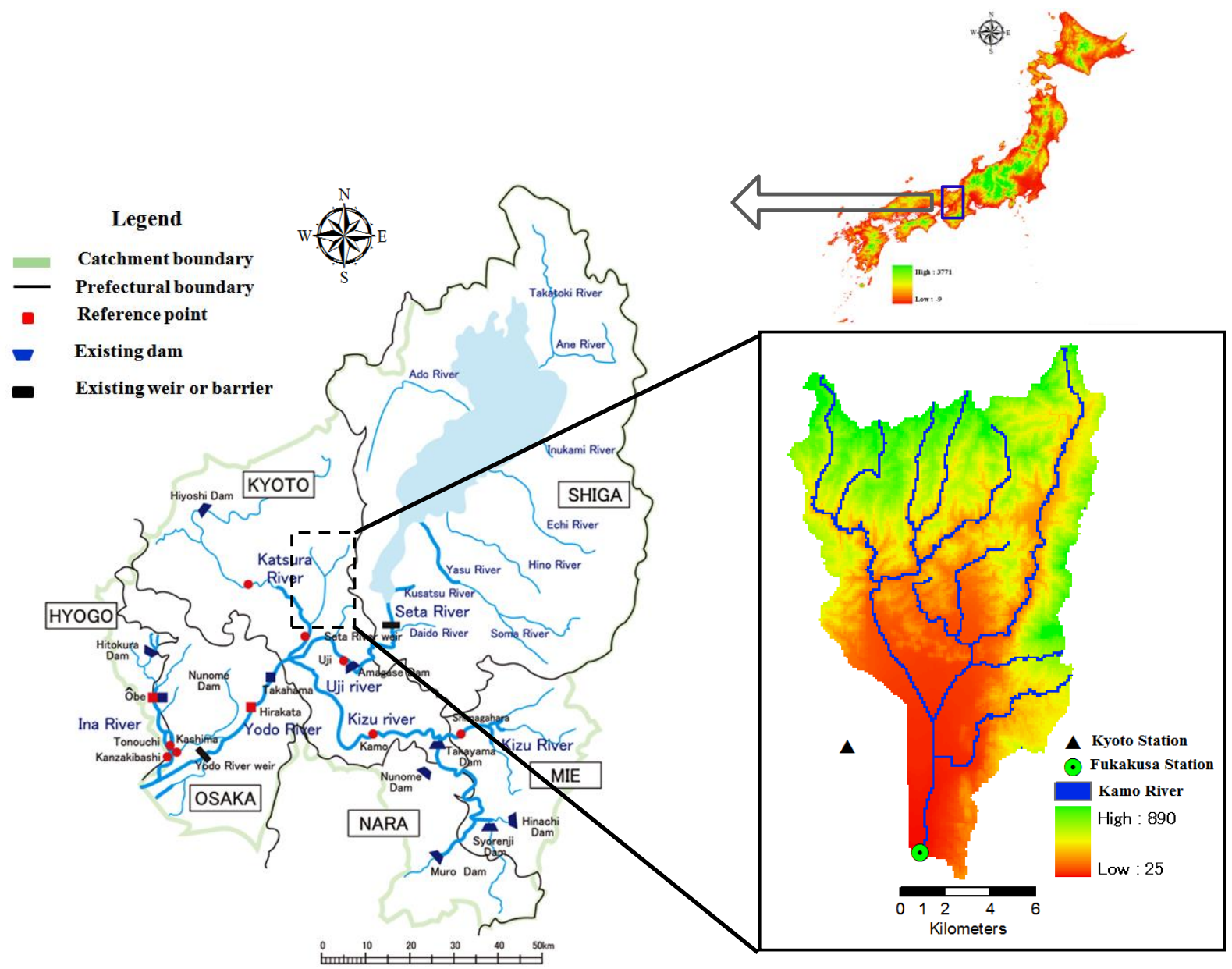

Fig.1 Location and Digital Elevation Map (DEM) (original source from MLIT) of the KRB 


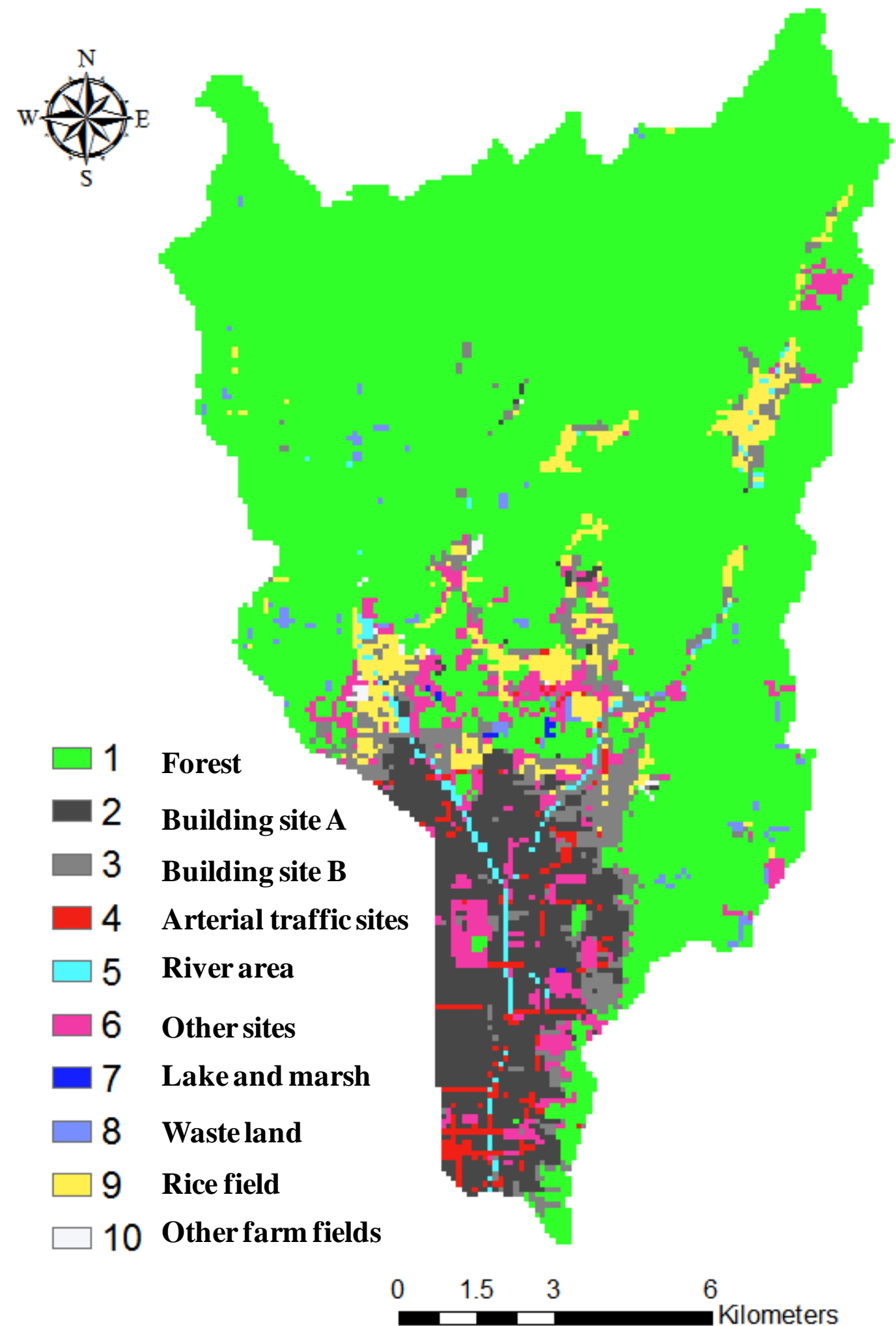

Fig.2 1976 Land-use (original source from MLIT) of the KRB (Building type A is high density residential, including residential streets, free-standing buildings and housing area with side lengths of more than $50 \mathrm{~m}$, as well as other tall and large buildings. Building type B is medium or low density residential, including free-standing buildings and housing with side lengths less than $50 \mathrm{~m}$.) 


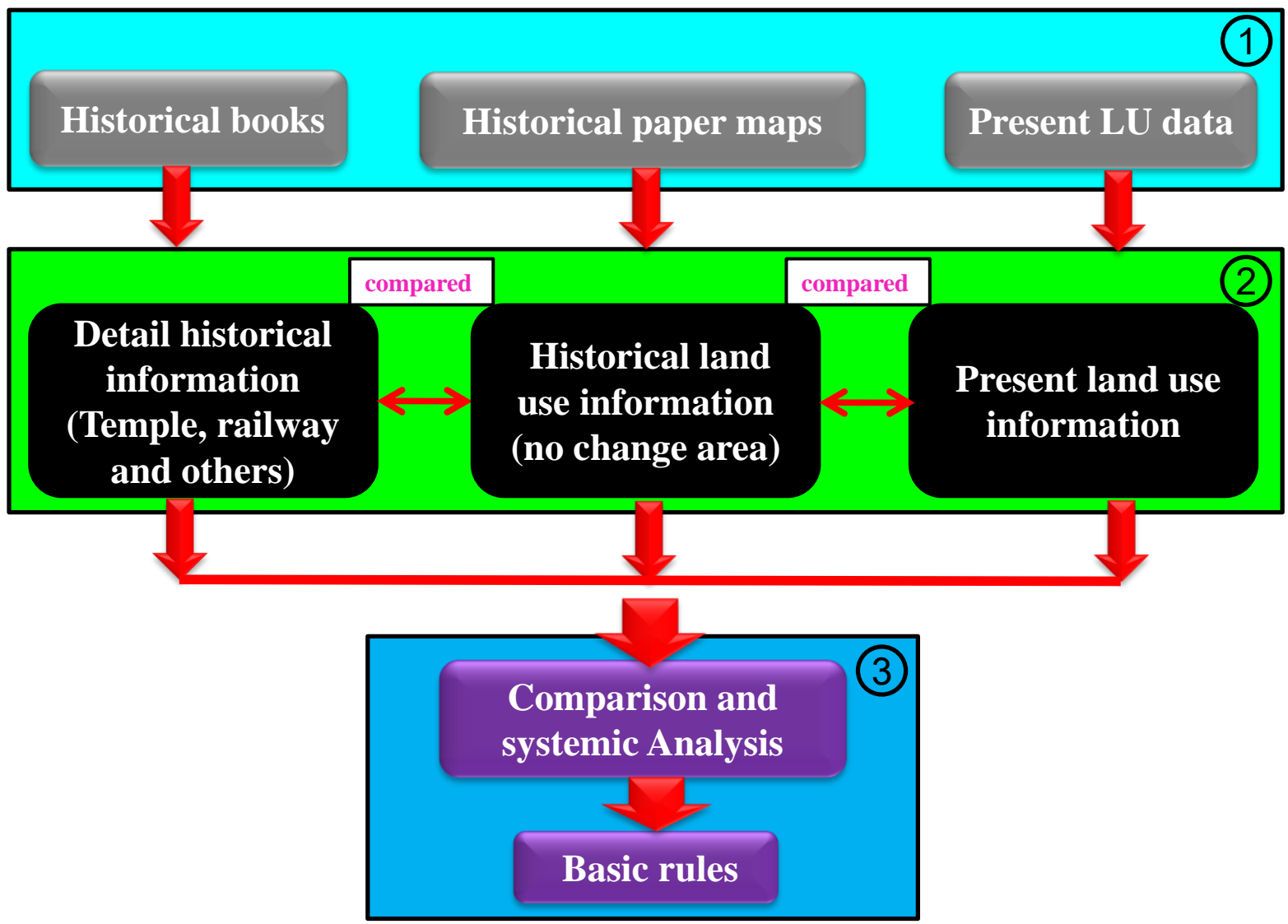

Fig.3 Process for building basic rules of historical reconstruction program 


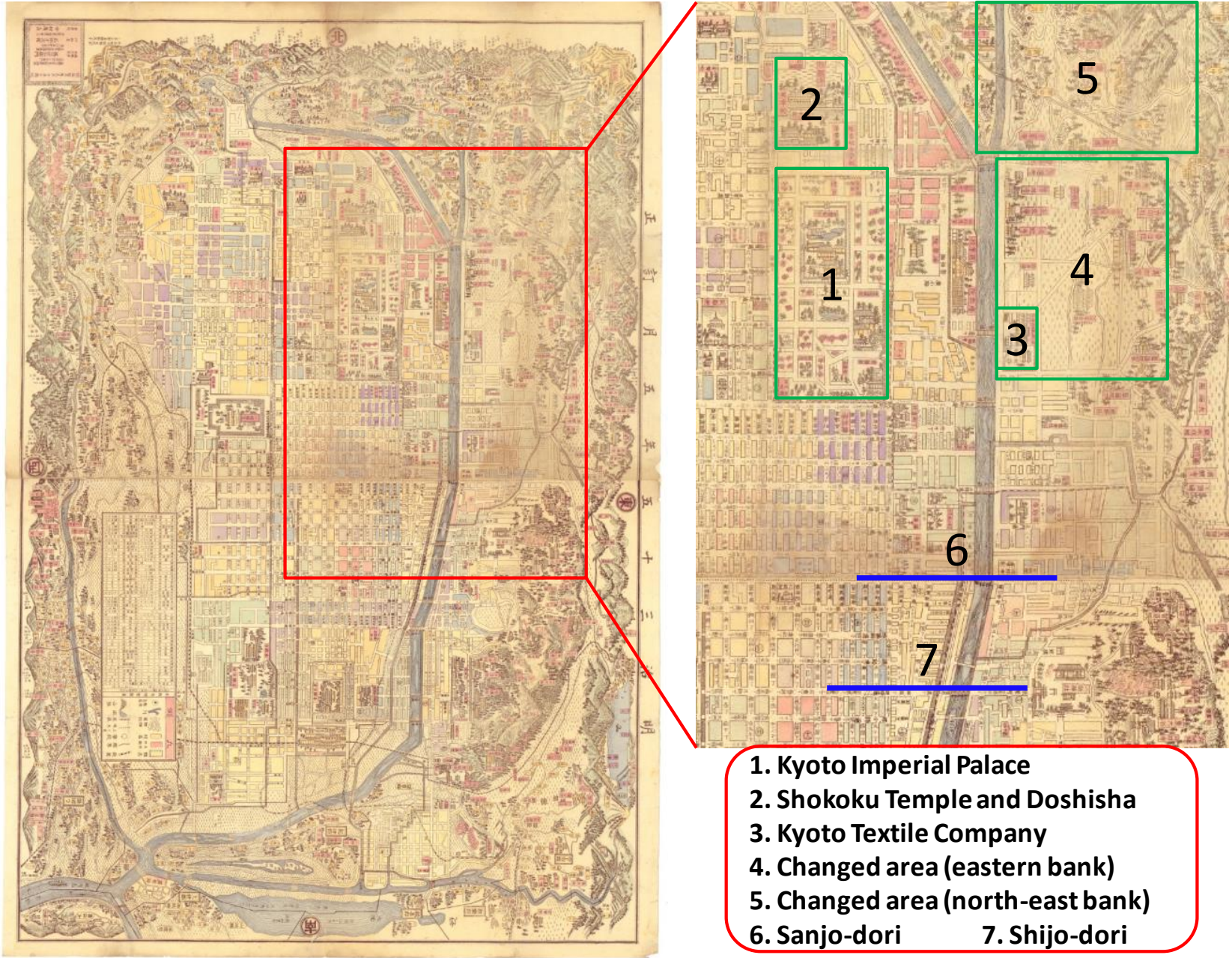

Fig.3 Historical document example of the Kyoto city land use in 1902 (original source from MLIT). 


\section{Vector data files}

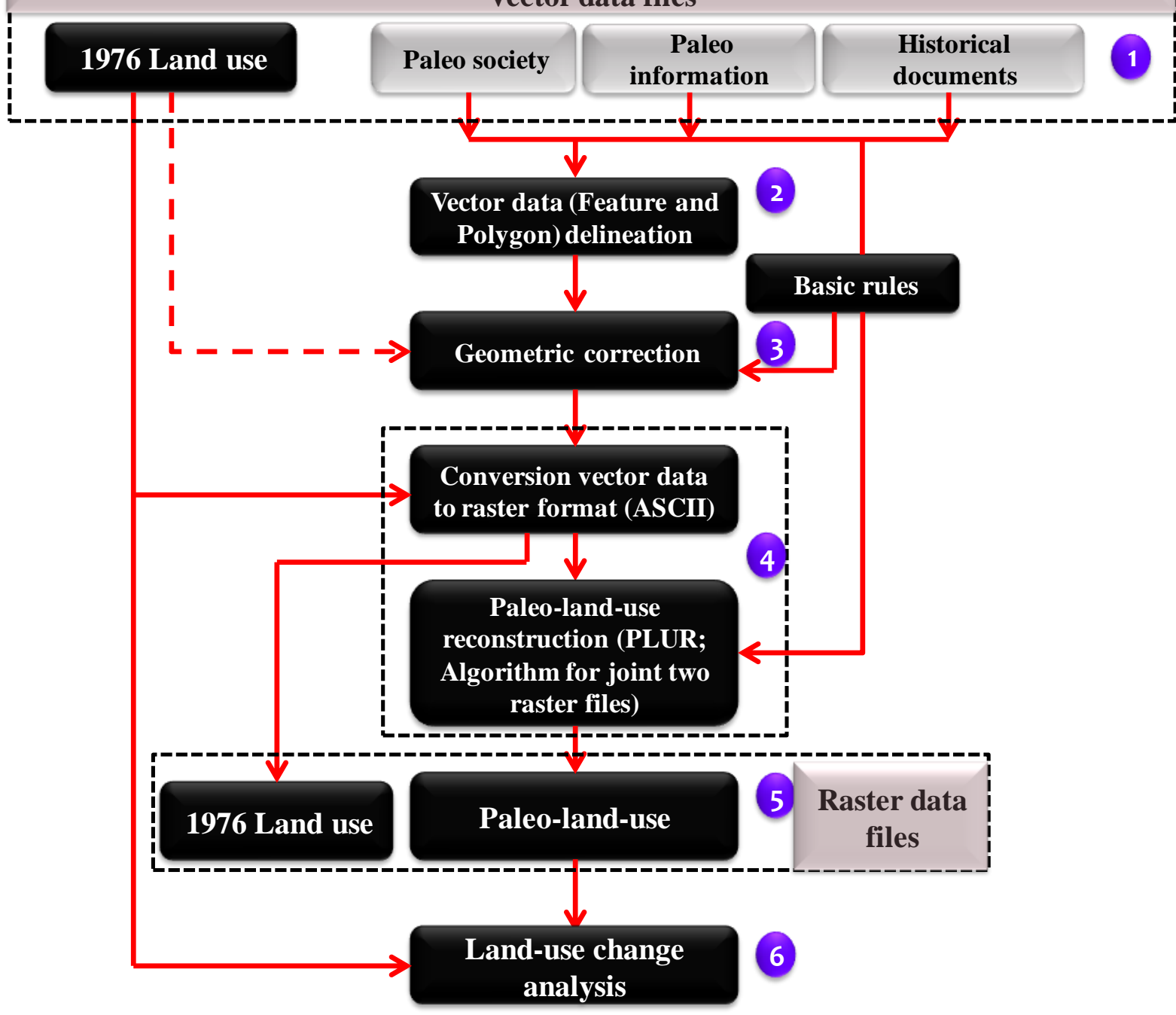

Fig.4 Framework for the historical land use reconstruction process using the PLUR program 

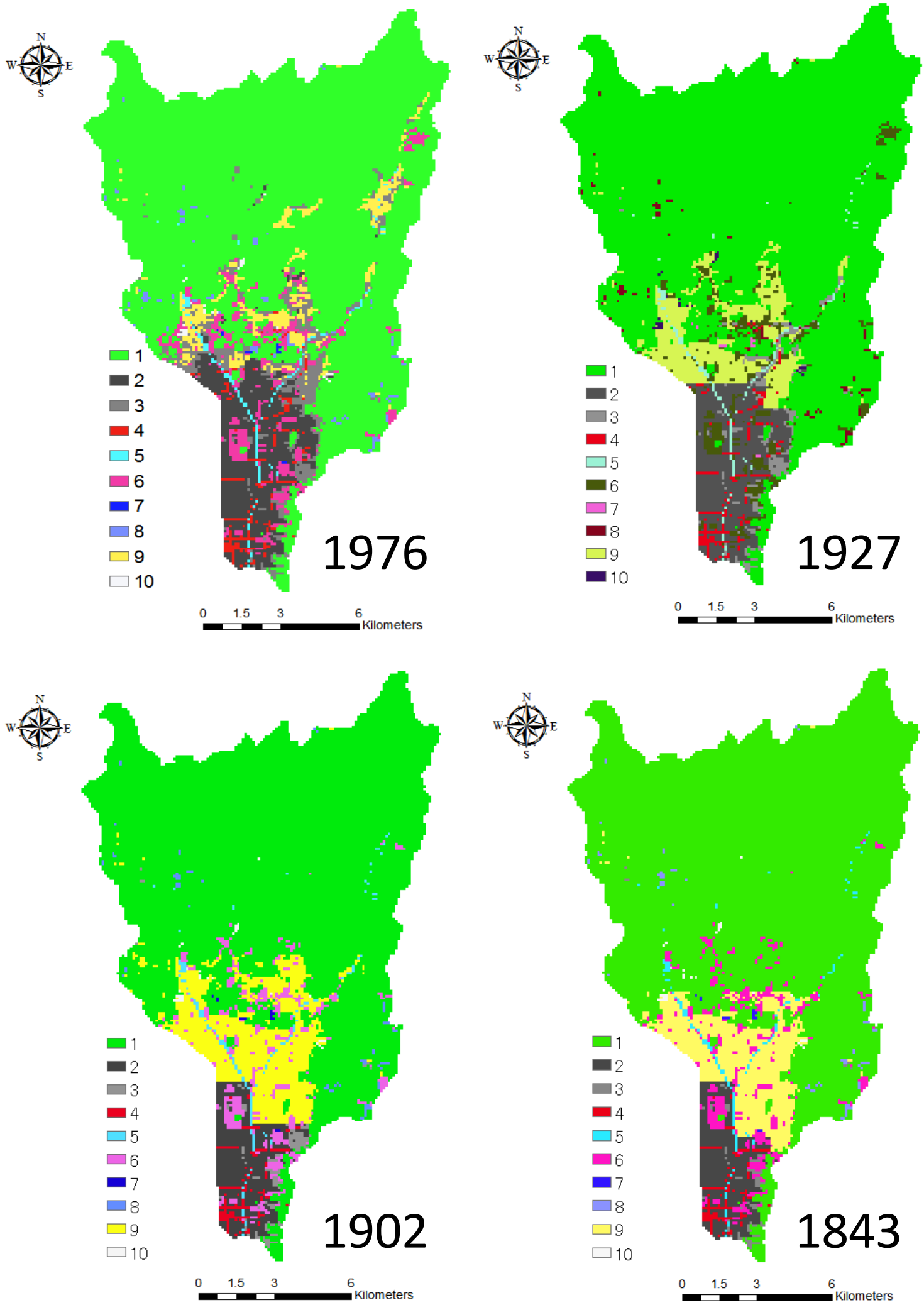

672

Fig. 5 Land use map of 1976, 1927, 1902 and 1843 (land use map of 1843, 1902, and 1927 is reconstructed using the PLUR program, land use map of 1976 is from MLIT). 


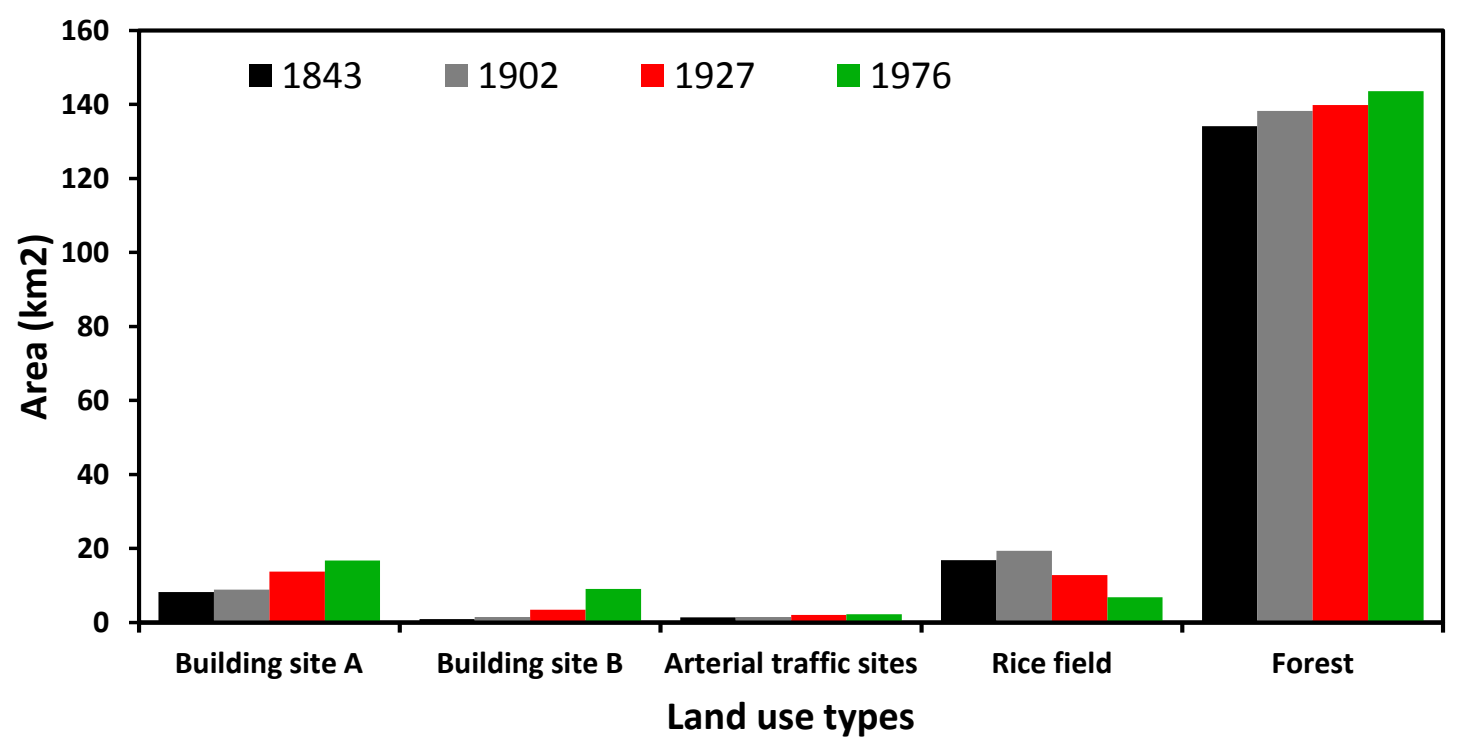

677

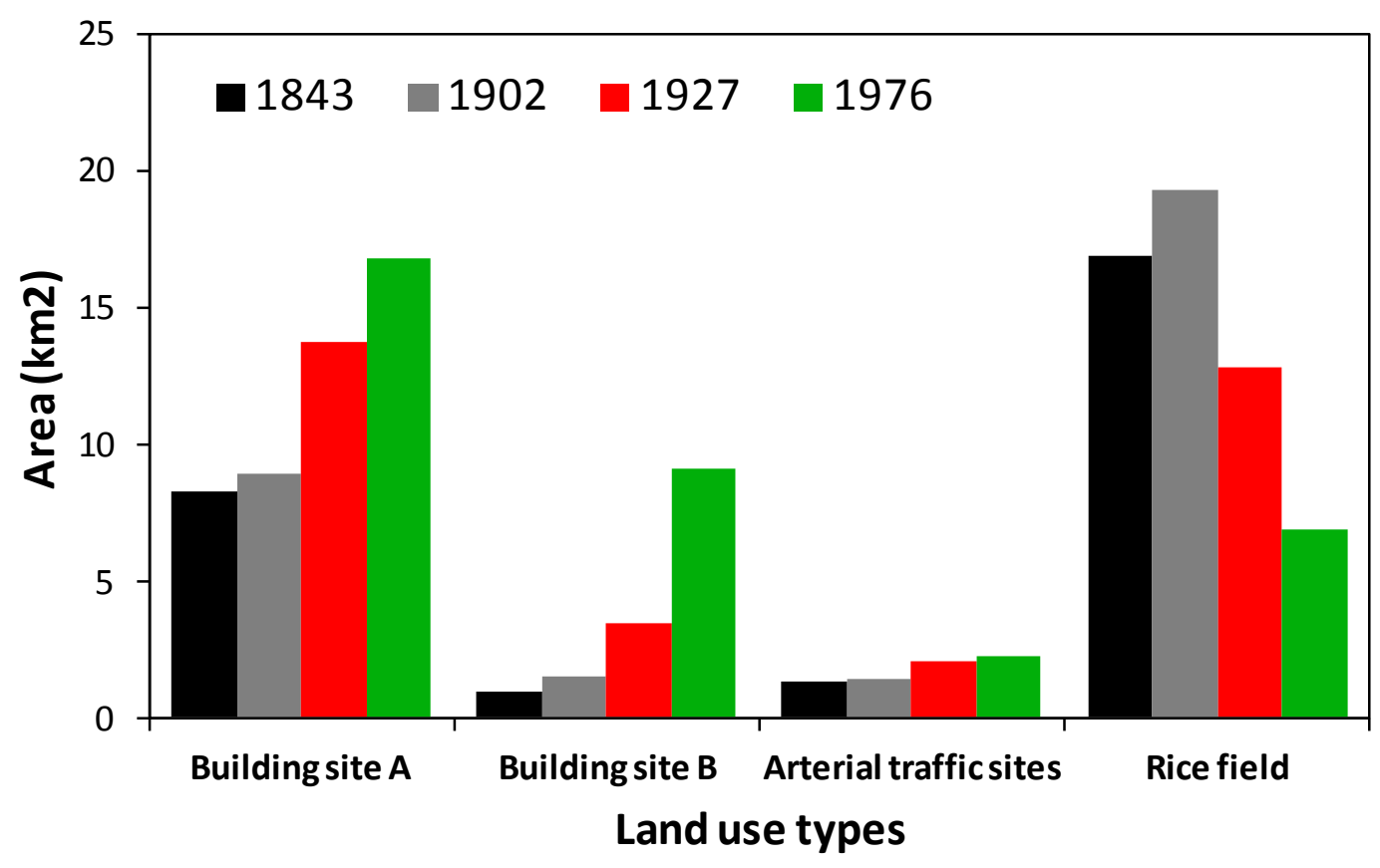

Fig. 6 Land use change among 1843, 1902, 1927 and 1976 (including Building sites A and B, Traffic site and Rice field, Building type A is high density residential, including residential streets, free-standing buildings and housing area with side lengths of more than $50 \mathrm{~m}$, as well as other tall and large buildings. Building type B is medium or low density residential, including free-standing buildings and housing 


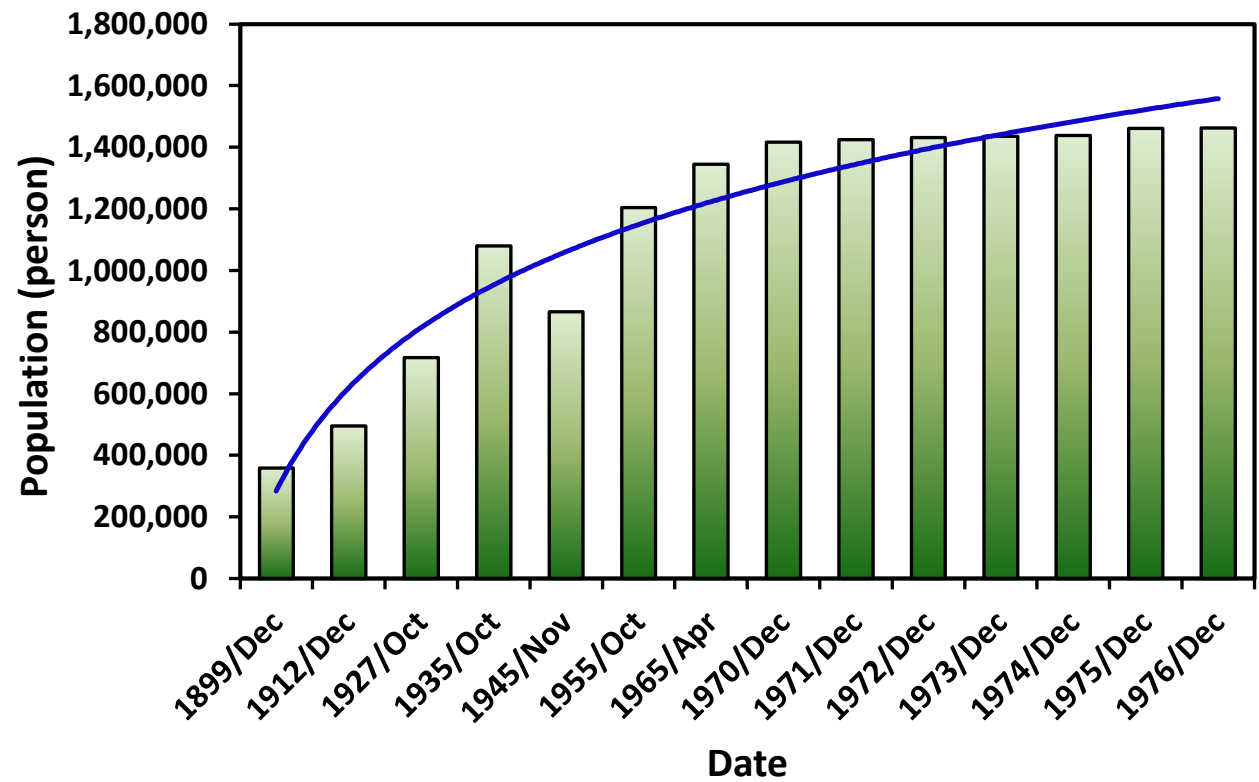

Fig. 7 Population of Kyoto city from 1899 to 1976 (Kyoto Marumie, 2013)

694

695

696

697

698

699

700 